\title{
INTERAÇÕES, PODER E INSTITUIÇÕES TOTAIS: ANARRATIVADE PRIMO LEVIEA MICROSSOCIOLOGIA DE ERVING GOFFMAN
}

\author{
Robson dos Santos
}

\begin{abstract}
RESUMO
A partir do relato biográfico e literário produzido pelo sobrevivente de um campo de concentração - o judeu italiano Primo Levi-, que descreve as estratégias de interação e representação adotadas pelo narradorsobrevivente para garantir a manutenção da vida, o presente artigo ensaia algumas reflexões sobre a Sociologia de Erving Goffman. O texto busca apreender os processos de produção da subjetividade e da individualidade no interior de uma instituição total, compreendendo o papel dos espaços sociais na construção de interações particulares, tal como aquelas que aconteceram num campo de extermínio, a partir do relato presente no livro "É isto um homem?", de Primo Levi. Essa análise nos conduz à reflexão sobre o micro e o macro na Sociologia de Goffman, bem como à indagação sobre a existência de uma teoria das instituições em sua Sociologia. Assim, ao adentrarmos essa dimensão da obra de Goffman com o auxílio da descrição da experiência de Primo Levi em uma instituição total, buscamos tanto dispor de uma narrativa diversa sobre o espaço em questão, quanto extrair alguns questionamentos para a própria concepção de Goffman, principalmente no que se refere às formas pelas quais sua Sociologia permite dinamizar as interações particulares, a história e as estruturas sociais exteriores ao território interacional. Ao que nos parece, uma análise das interações imanentes a locais delimitados não entra em contradição com a percepção e a análise dos processos sociais amplos: o campo de extermínio, por exemplo, instituiu e produziu sociabilidades próprias, das quais o entendimento, porém, não exclui a necessidade de se compreender o processo de emergência do nazismo, a história dos grupos perseguidos, bem como o sentido do Holocausto em relação ao chamado "processo civilizatório" ou a uma forma particular de racionalidade moderna.
\end{abstract}

PALAVRAS-CHAVE: interações simbólicas; literatura; instituições totais; Erving Goffman; Primo Levi.

\section{INTRODUÇÃO: ANARRATIVAE SUAS POS- SIBILIDADES DE COMPREENSÃO MICROSSO-CIOLÓGICA}

Acho desnecessário acrescentar que nenhum dos episódios foi fruto de imaginação (LEVI, 1988).

Nas últimas duas décadas, ganharam destaque, no campo dos estudos históricos e sociológicos da literatura, as investigações sobre as narrativas literárias de indivíduos que enfrentaram "situações limite", "atravessaram a morte" em condições sociais ou em instituições e decidiram escrever sobre o que haviam vivenciado, o que ficou mais conhecido como "literatura de testemunho"l. São aspectos característicos de tais

1 "O testemunho deve ser compreendido tanto no seu sentido jurídico e de testemunho histórico - ao qual o narrativas a ruptura com as fronteiras entre os gêneros literários e a consagração do hibridismo estético como forma de composição. A história, a literatura, a biografia, a documentação, a etnografia e as descrições sobre as trajetórias de vida imbricam-se no processo construtivo da literatura de testemunho, o que a aproxima da etnografia como descrição densa de uma experiência social. O exemplo mais paradigmático de tais criações pode ser vislumbrado num livro publicado em 1947: $\dot{E}$ isto um homem? Escrito pelo judeu italiano Primo Levi, após ser libertado do campo de concentração Auschwitz-Birkenau, o texto narra o período de 11 meses no qual o autor permaneceu preso, depois de ser capturado pelas tropas fascistas italianas e entregue aos soldados alemães, sob condições extremas de opressão física e moral. Tomado como uma das narrativas mais chocantes sobre o Holocausto e as técnicas de controle e extermínio utilizadas pelo nazi-fascismo, o texto expõe as "estratégias", "representações" e "aci- 
dentes" vivenciados pelo autor no interior de uma instituição total que, conjugados, permitiram que ele sobrevivesse.

O relato engloba uma dimensão literária, mas propõe-se também a ser uma narrativa das experiências traumáticas vivenciadas por Levi, bem como uma tentativa de construção de uma filosofia capaz de oferecer uma "explicação" sobre o Holocausto. O texto comporta ainda uma descrição detalhada do campo e das sociabilidades que o definem e que o produzem. Ele tem como intenção compor uma etnografia da dor e do sofrimento levados ao extremo por técnicas de dominação e de apropriação da subjetividade e da vida. Como revela o próprio autor no prefácio da narrativa: "Sou consciente dos defeitos estruturais do livro e peço desculpas por eles. Se não de fato, pelo menos como intenção e concepção o livro já nasceu nos dias do Campo. A necessidade de contar "aos outros", de tornar "os outros" participantes, alcançou entre nós, antes e depois da libertação, caráter de impulso imediato e violento, até o ponto de competir com outras necessidades elementares" (LEVI, 1988, p. 7-8).

A compreensão dos campos de extermínio comporta múltiplas possibilidades sociológicas. Por um lado, é possível buscar nos macro processos sociais as chaves para compreender-se a emergência de condições sociais, políticas e culturais, num contexto nacional e internacional específicos, que confluíram nos campos de extermínio e no nazi-fascismo como ideologia orientada pelo genocídio e pela eliminação do "outro", o que demanda necessariamente um entendimento dos processos étnicos, econômicos, culturais e históri$\cos$ de longa duração e referenciados em macroestruturas como a modernização e suas contradições, o ethos e o habitus de formações socioculturais específicas etc. (ELIAS, 1997). De outro lado, é possível e necessário compreender sociologicamente o tipo de relações sociais que caracterizavam o interior dessas "instituições" de eliminação, os atores que levavam a cabo o processo de rotinização do autoritarismo, da violência e da morte, as sociabilidades intrínsecas ao ambiente e as subjetividades que surgiam em tal cenário de controle permanente. Para tanto, é preciso reconstruir as dinâmicas localizadas, face to face, marcadas por um sentido exclusivo e único naquele espaço social em particular, isto é, uma microssociologia do campo de extermínio e das interações entre seus atores sociais frente à rigidez de seus papéis.

É nesse sentido que, a partir de algumas proposições da Sociologia de Erving Goffman, o artigo busca compreender as estratégias de sobrevivência do autor-personagem Levi, agente de sua narrativa, à luz de noções como instituição total, representação, interação, dramatização, atores, mortificação do eu, carreira moral etc. Tal proposição demanda que se compreenda a localização no interior da Sociologia de Goffman de uma teoria das interações autoritárias e da maleabilidade do ator, ou indivíduo, no seio de uma estrutura institucional que é, sobretudo, a "materialização" de uma conformação social e histórica. Profícua em compreender sociologicamente os espaços e estratagemas adotados pelos indivíduos em situações sociais concretas, na interação delimitada a situações e ambientes, bem como os mecanismos de manutenção e preservação da ordem social em espaços específicos, resta articular a Sociologia de Goffman, com as possibilidades e necessidades de se investigar as situações de interação espacialmente delimitadas, com uma reconstrução histórica de instituições e espaços sociais mais amplos, isto é, de uma tensão entre história e instituições e entre amplas configurações sociais e espaços de interação demarcados. Estes e os papéis que comportam parecem ter sentido somente ao serem compreendidos como etapas de processos sociais, marcados por relações que se referem, portanto, a situações possibilitadas pelas instituições em um determinado momento do seu processo de existência social e não como marcas genéticas de sua situação. A construção analítica de Goffman reserva pouco espaço para a compreensão da construção histórica dos fenômenos sociais, centrando-se no lócus físico da interação, tomada aparentemente como um momento desprovido de "antecedentes" e de "posteridade". Buscamos problematizar como sua sociologia privilegia o "lugar constituído", e não os processos de constituição, as representações no lugar das produções. É evidente que Goffman não ignorava ou desconhecia os processos sociais vinculados à produção de espaços e interações demarcadas, propomos apenas uma leitura crítica de sua sociologia a fim de apreender as dinâmicas de constituição da sociedade e de sociabilidades, onde o micro e o macro integram instâncias e faces do mesmo processo estrutural. 
Nesse sentido, analisando a narrativa de Levi a partir da sociologia de Goffman, buscamos apreender o espaço que as elaborações teóricas e analíticas da microssociologia desse autor reserva à história e a conexão entre as estruturas sociais "exteriores" e os tipos das interações efetivadas no interior de um espaço delimitado. Busca-se resgatar o debate sobre macro e microssociologia, mas também entre sociedade e espaços de sociabilidade - no caso, os campos de concentração , indagando, por fim, as possibilidades de uma teoria do poder na Sociologia de Goffman.

\section{O CAMPO DE EXTERMÍNIO E SUA “OR- DEM” SOCIAL COMO INSTITUIÇÃO TO- TAL}

A proposta de análise sociológica de Goffman diz respeito "à estrutura dos encontros sociais - a estrutura daquelas entidades da vida social que surgem sempre que as pessoas entram na presença física imediata uma das outras" (GOFFMAN, 2005a, p. 233). Seu foco recai sobre a vida social que é organizada dentro dos limites físicos de um prédio, de uma fábrica, de um ambiente que sintetize as relações sociais de um conjunto de atores. A narrativa de Primo Levi é justamente sobre a convivência entre indivíduos sob a permanente tensão da morte no interior de um espaço físico dotado de relações imediatas entre os atores, que tinham na interação com os demais integrantes do campo de extermínio nazista as possibilidades e impossibilidades de sobrevivência e que desenvolviam sociabilidades imanentes ao espaço da instituição total, repondo e/ou reconstruindo uma "ordem social" típica do campo de concentração. Os atores, no interior do campo, deviam abster-se dos "padrões" de conduta, das regras de sociabilidade exteriores, para apreenderem e procederem conforme o código do campo, que envolve o domínio de um conjunto de conhecimentos sobre o modus operandi, o habitus de uma instituição total: "A capacidade humana de cavar-se uma toca, de criar uma casca, de erguer ao redor de si uma tênue barreira defensiva, ainda que em circunstâncias aparentemente desesperadas, é espantosa e mereceria um estudo profundo. Trata-se de um precioso trabalho de adaptação, parte passivo e inconsciente, parte ativo: cravar um prego no beliche para pendurar os sapatos, à noite; ajustar tácitos acordos de não-agressão com os vizinhos; intuir e aceitar os hábitos e leis peculiares do Kommando e do Bloco. Graças a esse trabalho, depois de umas semanas consegue-se alcançar certo grau de segurança frente aos imprevistos; o ninho está feito, o trauma da mudança foi superado" (LEVI, 1988, p. 56)

Tal atributo da condição humana, imbricada às situações sociais especificas, conflui na narrativa de Levi a uma percepção da capacidade adaptativa dos indivíduos, que batalhavam constantemente para encontrar os mecanismos necessários à sobrevivência. Um detalhe na representação poderia confluir na eliminação do outro, o que se encaixava perfeitamente na lógica do campo de concentração como uma instituição total particular, que produz e conduz a modos de representar e organizar a vida e as relações sociais marcadas tanto por uma dimensão adaptativa, quanto regulada. $\mathrm{O}$ absurdo do campo de extermínio redunda numa normatização e numa normalização dos papéis e das representações num "estabelecimento social". A sobrevivência parece residir na adoção de uma ordem social diante do extraordinário, na constituição de espaços e de condutas sociais adequadas a um contexto no qual as ordens da sociedade não se aplicam. Como sugere a análise de Goffman (2005b), qualquer grupo de pessoas - prisioneiros, pilotos ou pacientes etc. - desenvolve uma vida própria que se torna significativa, razoável e normal, desde que você aproxime-se dela. Segundo o autor, uma boa forma de conhecer qualquer desses mundos é submeter-se à companhia de seus participantes, de acordo com as pequenas conjunturas a que estão sujeitos.

Um outro aspecto central da sociologia de Goffman é a compreensão das ordens sociais particulares não como aparências, epifenômenos de estruturas sociais amplas, mas como instâncias dotadas de sentido sociológico próprio. As instituições totais, em seu entender, não configuram evidências de uma sociedade disciplinar geral, mas são espaços sociais instituídos que comportam uma lógica social interna, própria. Nesse sentido, localizado no campo sociológico americano, ele afasta-se explicitamente das preocupações teóricas de sua época em torno das análises macrossociais, tal como as desenvolvidas pelo funcionalismo de Talcott Parsons (SCHEFF, 2007). Epistemologicamente, sua construção científica não se assemelha a qualquer forma de idealismo sociológico, que elabora previamente sistemas totais, estruturas amplas gerais e deduz as 
relações específicas como realização dessas dimensões globais. Sua Sociologia, ao contrário, chama a atenção para a necessidade premente de se investigar interações face-a-face e os aspectos sociais contidos nessas interações. Nesse sentido, se é possível falar em uma teoria do social em Goffman, é preciso defini-la e extraí-la das microanálises de eventos em que indivíduos localizavam-se frente uns aos outros, num espaço por ele denominado territorialidade interacional. Goffman não recusa a produção de uma teoria, mas ela só emerge da compreensão do próprio entendimento da ação. Sua abordagem não se abstêm da generalização dos princípios analíticos, pois seu intento é descrever uma série de aspectos que formam, juntos, um quadro de referência aplicável a qualquer estabelecimento social concreto, seja ele doméstico, industrial ou comercial (GOFFMAN, 2005a). Contudo, somente o conhecimento de cada instituição ou espaço de interação permite estabelecer a reflexão geral e comparativa. A dinâmica do agente social com a estrutura deve ser buscada nas formas de ser e de agir produzidas e significativas num lócus interacional com fronteiras físicas e morais discerníveis. Somente aí a ação pode ser inteligível e sociologicamente captada.

Ao resgatarmos a descrição de uma instituição total, é preciso entender essa dimensão conferida na análise de Goffman à teoria do social pensado não como totalidade ou estrutura do conjunto social, mas a teoria-descrição de uma ordem social demarcada. Assim, no interior da sociedade americana, por exemplo, as instituições prisionais comportam traços comuns, mas só podem ser entendidas a partir da compreensão das interações inerentes a cada instituição. É importante frisar que Goffman não recusa sociologicamente a existência de traços culturais e sociais comuns ao conjunto de uma sociedade, mas ao compreender as instituições totais, por exemplo, ele não objetiva "explicar" em última instância a sociedade na qual elas inserem-se, e sim os traços comuns das instituições em determinada sociedade, pois elas "parecem reunir muitos aspectos em comum - na realidade, tantos são esses aspectos que, para conhecer uma dessas instituições, é aconselhável considerar também outras" (GOFFMAN, 2005b, p. 16). É nesse momento de dinamização entre os traços peculiares e comuns das instituições que Goffman problematiza mais explicitamente os substratos teóricos que orientam seu projeto ana- lítico, em que busca conciliar as "características gerais" das instituições sem desembocar numa generalização teórica excessivamente abstrata: "Antes de tentar extrair um perfil geral dessa lista de estabelecimentos, gostaria de mencionar um problema conceitual: nenhum dos elementos que irei descrever parece peculiar às instituições totais, e nenhum parece compartilhado por todas elas; o que distingue as instituições totais é o fato de cada uma delas apresentar, em grau intenso, muitos itens dessa família de atributos. Ao falar de "características comuns", usarei a frase de uma forma limitada, mas que me parece logicamente defensável. Ao mesmo tempo, isso permite usar o método de tipos ideais, através do estabelecimento de aspectos comuns, com a esperança de posteriormente esclarecer diferenças significativas" (idem, p. 17).

A apropriação do conceito weberiano de tipo ideal confere, por sua vez, uma dimensão de abstração das características gerais das interações. Nesse sentido, ao efetuarmos uma análise do campo de concentração, por exemplo, é preciso, para entender esse espaço sociologicamente, além da compreensão do nazi-fascismo à luz da história e das estruturas sociais amplas, operar a apreensão dos meandros interacionais inerentes à instituição do campo de concentração, em sua especificidade física e temporal. Realizar tal conexão analítica, tomando a Sociologia de Goffman como referencial, exige um esforço de articulação e síntese com outras referências metodológicas, evitando que a investigação restrinja-se ao interior desses estabelecimentos, descontextualizando-os do meio em que se inserem, dos efeitos que provocam e dos serviços que prestam à sociedade mais ampla. Isso é importante para evitar uma espécie de coisificação ou autonomização absoluta das instituições, tomando-as como um dado da realidade por vezes isolado. Situação por vezes comum em etnografias inspiradas em correntes teóricas como a etnometodologia, o interacionismo simbólico ou no individualismo metodológico (BOURDIEU, 2007)

É evidente que o campo de extermínio não é dotado da mesma regularidade e historicidade de um hospital, um convento ou uma escola, instâncias centrais das análises desenvolvidas por Goffman acerca das instituições totais. Ele é um "evento" peculiar de um contexto histórico-social marcado pelo absurdo, mas isso não o exime de constituir relações sociais próprias, formas regu- 
lares de atividades e de interações entre atores, ele demanda inclusive, como bem o demonstra a narrativa de Levi, manipulações mais ou menos eficazes da impressão. É nisso que reside uma das dimensões sociais do campo de concentração, tal como descrita em É isto um homem? A composição rápida de ordens sob o atípico do campo e de camadas de regras que não aquelas representadas nos regulamentos da instituição e da equipe dirigente. Mas essas ordens atrelam-se em muito às relações prévias elaboradas na trajetória social dos atores. Por isso, como relata Levi, ser tão comum a composição de grupos no interior do campo, organizados a partir da nacionalidade, das vinculações étnicas e classistas que compõem, por sua vez, atributos que precedem a inserção do indivíduo no campo, que se relacionam à historicidade das trajetórias. A ordem interacional do campo impunha a "mortificação do eu", a supressão dos traços comuns prévios, numa desumanização e numa descaracterização próprias, mas a ordem interacional que emerge sob a ordem do campo, acaba por repor as identidades e comunidades que antecedem a inserção na instituição, tais como as filiações ideológicas, religiosas, de classe, étnicas etc. O que demanda da análise das interações um reconstituição das trajetórias, não como tentativa de encontrar uma teleologia dos destinos, uma racionalidade que confluiria no campo, mas como critério importante para o entendimento das subjetividades que emergem no campo, considerando que essas não são produzidas sobre uma tábula rasa, mas sob representações, valores e crenças produzidas e partilhadas antes do indivíduo adentrar no campo.

A inserção na lógica do campo de extermínio não é um processo prévio para o qual é possível "preparar-se", como não é a introdução na maioria das instituições totais descritas por Goffman. As estratégias de sobrevivência devem ser buscadas no decorrer da inserção, no processo de construção do "eu" típico do campo de extermínio: "Aqui estamos todos, trancados, nus, tosquiados e de pé, com os pés na água, é a sala das duchas. Estamos sozinhos; pouco a pouco o assombro cede, falamos, todo mundo pergunta, ninguém responde. Estarmos nus numa sala de duchas, quer dizer que não nos vão matar - ainda" (LEVI, 1988, p. 22).

Os mecanismos de construção do "eu" no campo cumprem um ritual gradual de inserção. Como aponta Goffman, nas instituições totais o mecanismo completo de produção do "eu" é lento e às vezes se rompe expondo seus diversos componentes, desnudando a engenharia social que o reproduz: o controle da região dos fundos; a conivência da equipe; o tato da platéia; e assim por diante: "Mas, sendo bem lubrificado, as impressões fluirão dele com bastante rapidez para nos colocar no domínio de um dos nossos tipos de realidade. A representação se realizará e o firme 'eu' conferido a cada personagem representado parecerá emanar intrinsecamente de seu ator" (GOFFMAN, 2005a, p. 232).

A eficácia "desumanizadora" do campo de extermínio descrita por Levi realizava-se na construção delimitada de papéis e espaços reservados para cada um dos grupos de atores. Esses não eram compostos somente da oposição central entre guardas e prisioneiros, mas também entre os diversos tipos de prisioneiros. A racionalidade do campo de extermínio não se apresentava exclusivamente no uso do trabalho escravo e nas técnicas de eliminação, mas também na construção de papéis que passavam a ser vislumbrados como intrínsecos aos atores. A inserção no campo, como aponta Levi, era a incorporação, no sentido de corporificação, de atributos e disposições indispensáveis à sobrevivência nesse espaço. Essa inserção era acompanhada de uma série de rituais de entrada, de demarcações dos papéis e das dramatizações necessárias à criação do efeito de inserção e a automatização corpórea e psíquica, tal como o habitus descrito por Bourdieu (2007), das regras do campo de extermínio: "Ao que parece, esta é a verdadeira iniciação: só 'mostrando o número' recebe-se o pão e a sopa. Necessitamos de vários dias e de muitos socos e bofetadas, até criarmos o hábito de mostrar prontamente o número, de modo a não atrapalhar as cotidianas operações de distribuição de víveres; necessitamos de semanas e meses para acostumarmo-nos ao som do número em alemão. E durante muitos dias, quando o hábito da vida em liberdade me levava a olhar a hora no relógio, no pulso aparecia-me, ironicamente, meu novo nome, esse número tatuado em marcas azuladas sob a pele" (LEVI, 1988, p. 26).

O campo de concentração, tal como a fábrica ou um prédio, constitui um estabelecimento "social concreto", dotado de limites físicos e de poder extremamente demarcados por "barreiras estabelecidas à percepção, no qual se realiza regularmente uma forma particular de atividade" (GOFFMAN, 2005b, p. 218). As representações 
que se operavam nele impunham aos atores, soldados ou prisioneiros, dramatizações trágicas das relações. No entanto, é fundamental ressaltar que a distribuição dos papéis era profundamente assimétrica: um lado da platéia recorria, quando insatisfeita com a interpretação, à força das armas. Situação essa que condicionava em muito as possibilidades "teatrais" - conforme a metáfora de Goffman - dos prisioneiros e oferece um dado relevante para a microssociologia das relações de poder encenadas. Essa nota é fundamental ao regatarmos uma das intenções centrais da Sociologia de Goffman, isto é, a compreensão da maneira pela qual o indivíduo apresenta, em situações comuns de trabalho, a si mesmo e a suas atividades às outras pessoas, os meios pelos quais dirige e regula a impressão que formam a seu respeito e as coisas que pode ou não fazer, enquanto realiza seu desempenho diante delas. O comum, evidentemente, não é o comum da "vida antes do campo", como ressalta Levi, mas o comum do interior da instituição total, a rotina que se estabelece num espaço demarcado.

Segundo Goffman, as instituições totais constituem estabelecimentos fechados que funcionam em regime de internação ou aprisionamento, em que um "grupo relativamente numeroso de indivíduos vive em tempo integral, separados da sociedade mais ampla por considerável período de tempo, levam uma vida fechada e formalmente administrada" (idem, p. 11). As instituições totais concentram a maioria das atividades dos indivíduos, quase todas as ações da vida do sujeito são efetuadas no mesmo local e sob uma única autoridade, sendo controladas por horários rígidos e vitais. A micro-física do poder nas instituições totais pauta-se na demarcação dos papéis de autoridade e de submissão, entre os prisioneiros famélicos e os guardas SS alemães: "Existe uma divisão básica entre um grande grupo controlado, que podemos denominar o grupo dos internados, e uma pequena equipe de supervisores" (idem, p. 18). Esses papéis de autoridade e submissão apresentavam-se, inclusive, entre os próprios prisioneiros, conforme a descrição de Levi.

Assim como o campo de concentração descrito por Levi, Goffman ressalta que a instituição conquista e impõe o tempo e o interesse de seus integrantes e lhes dá algo de um mundo diverso do mundo social exterior; essa diferenciação do mundo externo apresenta-se, sobretudo, no fe- chamento físico: "Seu 'fechamento' ou seu caráter total é simbolizado pela barreira à relação social com o mundo externo e por proibições à saída que muitas vezes estão incluídas no esquema físico - por exemplo, portas fechadas, paredes altas, arame farpado, fossos, água, florestas ou pântanos. A tais estabelecimentos dou o nome de instituições totais" (idem, p. 16).

O campo de extermínio congrega condições físicas delimitadas de uma instituição total e as características de fechamento que definem tais estabelecimentos. Os limites e barreiras físicas convertem-se em fronteiras de sociabilidade e interação. A "vida social" e suas possibilidades terminam nas cercas que circundam o estabelecimento: "Já temos idéia da topografia do campo: este nosso Campo é um quadrado de uns seiscentos metros de lado, fechado com duas cercas de arame farpado, sendo a de dentro ligada à corrente de alta tensão. Consta de sessenta barracos de madeira, aqui chamados Blocos; destes, uma dezena ainda está em construção. [...] No meio do Campo está a Praça da Chamada, imensa, onde se reúne cada manhã para formar os grupos de trabalho, e à noite para ser contado. Na frente da praça há um canteiro, com a grama cuidadosamente aparada: lá são armadas as forcas, quando necessário" (LEVI, 1988, p. 30-31).

Esse fechamento, sobretudo físico, redunda no surgimento de relações sociais fechadas e restritas às condições específicas do campo. Essa é uma conclusão importante para o entendimento da Sociologia de Goffman. A sociedade não produz relações compreensíveis fora do âmbito das instituições e espaços sociais que circundam encontros e interações físicas. Os atores se articulam com estruturas localizadas e são essas, e o entendimento de sua ordem própria, que permite a reflexão, em Goffman, da dinâmica entre subjetividade e objetividade, ou entre o mundo psíquico e o mundo social, jamais apreendidos de forma separada, mas como intrínsecos às representações da interação.

\section{OS ATORES E OS PAPÉIS: A ASSIMETRIA DAS INTERAÇÕES}

As demarcações de autoridade no seio das instituições apresentam-se pela existência de uma equipe dirigente que exerce o gerenciamento administrativo da vida na instituição, o que no caso do campo de concentração era exercido pelos 
soldados alemães da $S S$, uma espécie de polícia nazista de elite, sobre os prisioneiros. A Sociologia das instituições totais desenvolvida por Goffman descreve detalhadamente as interações que os dois grupos centrais da instituição total executam: há modelagem e adaptações; uma expiação permanente e recíproca, evidentemente com assimetrias, visto que a apropriação do poder é desigual. Depreende-se de tal constatação, que as instituições não possuem uma existência meramente formal e administrativa, na medida em que elas se realizam substancialmente nas ações dos atores que a integram. A interação é tomada como um ato de sentido, uma forma de ação social localizada num ambiente de relação entre os atores, semelhante àquilo que Max Weber denominou "agir em comunidade", isto é, quando a ação humana se "refere de maneira subjetivamente provida de sentido ao comportamento de outros homens" (WEBER, 2001, p. 323). Nesse ponto, a sociologia das interações de Goffman aproxima-se em muito da idéia de ação social de Weber $^{2}$. O agir no interior da instituição é uma forma de "agir em sociedade", isto é, da sociedade intrínseca à instituição ${ }^{3}$.

É interessante notar que, no interior das instituições totais, o grupo dos internados ou prisioneiros tenta defender-se das estratégias conformadoras por meio de múltiplas táticas adaptativas e servindo-se, em certa medida, de vários recursos da própria instituição para confeccionar um mundo pessoal oposto aos objetivos oficiais do estabelecimento, ou uma ordem

2 Tal aproximação verifica-se também, entre outras, na apropriação do conceito weberiano de tipo ideal, utilizado por Goffman para expor sua concepção genérica das instituições totais.

3 'Denominamos 'agir em sociedade' um agir em comunidade na medida em que 1) se orienta, de maneira significativa, por expectativas que são alimentadas com base em regulamentações, 2) na medida em que tal 'regulamentação' foi feita de modo puramente racional com relação a fins, tendo em mente o agir esperado dos associados como conseqüência, e quando 3) a orientação provida de sentido se faz, subjetivamente, de maneira racional com relação a fins. Uma organização com "regulamentos" num sentido puramente empírico é, ou 1) um convite de uns homens a outros, expresso unilateralmente e, no caso limite, racional explicitamente, ou 2) uma explicação recíproca bilateral, feita de maneira explícita no caso limite, com o conteúdo subjetivamente declarado de que seja previsto e se espere um determinado modo de agir" (WEBER, 2001, p. 325). dentro da instituição total, mas fora da ordem dessa instituição. Nesse ponto, é relevante notar que, na análise da dinâmica entre ator e estrutura, Goffman recusa o entendimento do ator como absolutamente "determinado" pela instituição, como um fragmento individual que constitui apenas um reflexo sintético da estrutura institucional. Subjaz em sua teoria uma perspectiva de que os atores também realizam a instituição. Isso coloca sua interpretação da relação ator-estrutura numa posição de dinâmica: a subjetividade comporta elementos da objetividade, mas essa pode ser reinterpretada e, em partes, ressignificada pelos atores. Resta indagar, porém, se ela pode ser refeita, reconstruída, ou seja, se há espaço para a "emancipação" dos atores, principalmente os internos, em relação às estruturas da instituição total ${ }^{4}$.

A compreensão dessas interações, como esclarece a Sociologia de Goffman, implica uma compreensão das dinâmicas de poder implícitas nas representações e nos atos de interação. Para Goffman, o próprio poder recorre a rituais de representação que objetivam institucionalizar e legitimar a representação do poder. No campo de extermínio descrito por Levi, isso fica claro, por exemplo, na narrativa da música que era permanentemente tocada quando os prisioneiros caminhavam para o trabalho pela manhã e ao regressarem à noite. Aqueles que perdessem o compasso entre os movimentos da marcha e o ritmo da música eram duramente punidos. Apresentam-se também nos rituais de contagem dos prisioneiros, nas exigências das falas, dos gestos impostos pela interação com a "equi-

\footnotetext{
4 É interessante compreender a diferenciação entre ator e agente que parece subsistir, por exemplo, ao compararmos a Sociologia de Goffman com a de Pierre Bourdieu. O ator apresenta-se numa situação específica, interacional; o agente também realiza tais operações, contudo, suas tomadas de posição ocorrem não apenas em relação às condições de uma situação dada, mas sim a partir dos vários capitais que subsidiam sua ação prática, a partir do habitus que conforma suas disposições e modos de percepção. O habitus do agente possui a historicidade de sua constituição, de sua incorporação, ininteligível sem a compreensão dos múltiplos capitais e sua apropriação ao longo da trajetória do agente. $\mathrm{O}$ ator evidentemente não é um ser desprovido de códigos e de uma existência social que antecedem a situação interacional, contudo, ele só pode e deve ser compreendido em relação a situações sociais ou interacionais específicas, em ordens sociais localizadas. Os modos de agir e as disposições do ator são aquelas produzidas e disponibilizadas no estabelecimento ou no espaço da interação, e não apropriadas e corporificadas na trajetória social.
} 
pe dirigente", na audiência pública das execuções punitivas, que almejavam servir de exemplo, de consagração do poder e de desencorajamento das ações de oposição. Tais rituais informam uma etapa decisiva naquilo que Goffman definiu como "carreira moral" dos internos, pensada como trajetória na vida dos prisioneiros no espaço de reclusão. A "carreira moral" articula-se na teoria sociológica de Goffman a sua visão dinâmica entre subjetividade e instituições, pois "o conceito de carreira permite que andemos do público para o íntimo, e viceversa, entre o eu e sua sociedade significativa" (GOFFMAN, 2005b, p. 112).

A sociologia de Goffman é, em certa medida, a busca por elaborar uma análise da construção do "eu" no interior das instituições, uma "versão sociológica da estrutura do eu", ou o "estudo institucional do eu". Em termos teóricos, tal concepção confere a sua análise uma perspectiva nãoessencialista, nem espiritualista, pois o "eu", para Goffman, é uma construção social e não um atributo metafísico naturalizado. A partir disso é instigante pensar como a narrativa de Primo Levi descreve o processo do "eu" sendo construído no interior de uma instituição e que explicita, como um integrante participante das sociabilidades do campo de concentração, o tipo de "eu" estruturado no campo. Levi foi um prisioneiro e, segundo ele, sua compreensão da situação vivenciada só poderia ser entendida a partir da apreensão dos pequenos gestos impetrados no seio da instituição. Afinal, "é um homem quem mata, é um homem quem comete ou suporta injustiças" (LEVI, 1988, p. 173). Mas as capacidades e as possibilidades adaptativas do ator no interior do campo são "fechadas" pelas regras do local. Os homens que se agridem, matam-se, convivem ou ajudam-se, o fazem a partir de condições dadas e sobre as quais restam poucas possibilidades de reversão a partir das interações efetivadas sob a hegemonia do campo de concentração. Esse produz e reproduz a sua ordem, deixando poucos espaços e possibilidades para o surgimento de sua auto-dissolução.

A introdução no campo de concentração é marcada por uma inserção física, mas também por uma inserção cultural e social. $\mathrm{Na}$ desconstrução do "eu" para a construção do "eu" da instituição, a violência irrompe na apropriação institucional da subjetividade ou na produção de uma "subjetividade" do campo de concentração. Como bem ressalta a Sociologia das instituições totais: "O novato chega ao estabelecimento com uma concepção de si mesmo que se tornou possível por algumas disposições sociais estáveis no seu mundo doméstico. Ao entrar, é imediatamente despido do apoio dado por tais disposições. $\mathrm{Na}$ linguagem exata de algumas de nossas instituições totais, começa uma série de rebaixamentos, degradações, humilhações e profanações do eu. $\mathrm{O}$ seu eu é sistematicamente mortificado. Começa a passar por algumas mudanças radicais em sua carreira moral, uma carreira composta pelas progressivas mudanças que ocorrem nas crenças que têm a seu respeito e a respeito dos outros que são significativos para ele" (GOFFMAN, 2005b, p. 24).

A Sociologia de Goffman não desenvolve uma história das instituições, ou mesmo uma reconstrução genealógica das sociedades disciplinares, como em Foucault (1977). Mas ela não abdica, porém, de desenvolver uma história dos atores e da constituição das interações em ambientes e instituições definidas. A historicidade de sua Sociologia não se verifica no nível das estruturas sociais amplas e gerais, mas sim nas estruturas particulares das instituições. Um conceito que parece denotar claramente tal concepção é o de carreira moral. A do prisioneiro do campo, tal como descrita por Levi, era a trajetória social de apropriação da vida no campo de extermínio, que rondava permanentemente a morte. Tal instituição inscrevia nos atores uma noção teleológica dos destinos, isto é, a morte já parecia estar contida nos atos de iniciação.

Os companheiros de campo eram gradualmente transformados em "grupos" humanos genéricos, "os ingleses", "os judeus", "os poloneses" etc. Essas classificações coletivas, porém, comportavam ainda certa individualidade, que ia sendo suprimida na definição de apenas dois grupos sociais entre os prisioneiros: os que se salvavam e os que se afundavam, isto é, entre os que sobreviveram e os que morreram. Se, para Goffman, o $e u$ do indivíduo, ou ator social, é um elemento socialmente construído diante das interações sociais com os demais atores, para Levi a situação parece ser semelhante: "uma parte de nossa existência está nas almas de quem se aproxima de nós" (LEVI, 1988, p. 174).

\section{CONSIDERAÇÕES FINAIS}

A Sociologia de Goffman constitui uma importante construção analítica, oposta aos projetos de constituição de modelos gerais e universais, característicos do funcionalismo, entre outras 
correntes sociológicas. Ao elaborar uma análise sociológica que seja profícua no desenvolvimento de investigações sociais que não compusessem etapas de comprovação de uma teoria previamente constituída, Goffman busca dinamizar a investigação empírica de universos sociais delimitados, de interações físicas, mas não necessariamente desprovidas de dimensão simbólica, com a apresentação de uma teoria não-universal das instituições totais.

Goffman não constrói um corpo puramente conceitual e metodológico, pensado de forma autônoma, um tipo de "teoria pura", mas isso não exclui a existência de uma teoria social em sua obra. Ele desenvolve uma apreensão do local da interação, o que não significa que elabore apenas uma descrição do vivenciado, mas sim uma observação que busca classificar teoricamente os processos e ações, tal como demonstram seus conceitos de "papel", "ator", "equipe dirigente", "instituição total" etc.

Por trás de sua investigação das interações específicas nas instituições totais, subsiste uma concepção de que as ordens sociais particulares produzem nos atores um "eu" do estabelecimento, uma reconfiguração, com traços tanto provisórios quanto permanentes, das subjetividades. É essa orientação que direciona suas análises sociológicas.

Ainda no plano teórico, é importante destacar que a conceituação das instituições totais feita por Goffman oscila entre um tipo ideal e a descrição das especificidades de cada instituição. Além disso, é preciso deixar claro que micro e macro nada têm a ver com tamanho - o grande: a Sociedade, o Estado; e o pequeno: os indivíduos e suas relações intra e interindividuais. Não se trata de uma diferença de grau, mas de natureza dos fenômenos (LOBO, 2004). Nesse sentido, o que enquadra sua Sociologia no interior da análise dos microcosmos sociais é justamente a centralidade da investigação sobre a física das relações, isto é, o momento mesmo da interação entre os corpos individuais. É relevante destacar que essas dinâmicas compõem situações inerentes inclusive às macro-estruturas sociais. É talvez a mediação entre essas dimensões não-antagônicas, o universal e o particular, que a análise de Goffman não se propõe a realizar, pois é centrada no lócus da ação e da experiência interacional, que deve ser experimentada por uma Sociologia que busque dinamizar a interpretação geral com a investigação das situações particulares.

Assim, ao adentrarmos uma dimensão da obra de Goffman com o auxílio da descrição da experiência de Primo Levi em uma instituição total, buscamos tanto dispor de uma narrativa diversa sobre o espaço em questão, quanto extrair alguns questionamentos para a própria concepção de Goffman, principalmente no que se refere às formas pelas quais sua Sociologia permite dinamizar as interações particulares, a história e as estruturas sociais exteriores ao território interacional.

Ao que nos parece, uma análise das interações imanentes a locais delimitados não entra em contradição com a percepção e a análise dos processos sociais amplos. O campo de extermínio instituiu e produziu sociabilidades próprias, das quais o entendimento, porém, não exclui a necessidade de se compreender o processo de surgimento do nazismo, a história dos grupos perseguidos, bem como o sentido do Holocausto em relação ao chamado processo civilizatório, ou de uma forma particular de racionalidade moderna. Essa, porém, não constitui a intenção de Goffman. Nesse sentido, a análise aponta a necessidade de articular o conhecimento do lócus da interação, considerando sua relação com o conjunto da sociedade que comporta determinada instituição, bem como o sentido e a localização dessa no interior daquela. E articular, sobretudo, a dimensão empírica com a construção sutil da teoria social, não como corpo insulado, mas como construção pensada e repensada a partir dos dados. Tarefa que Goffman efetua com grande maestria.

Além disso, cabe ressaltar a posição híbrida que uma narrativa de testemunho ocupa, pois ela envolve necessariamente uma relação entre a experiência individual e a estrutura que a produziu, bem como uma densa mobilidade entre construções narrativas distintas, como a biografia, a etnografia, a literatura e a história. O testemunho que resulta daí irrompe como transposição narrativa de uma experiência particular com um profundo sentido social.

Robson dos Santos (relvalins@yahoo.com.br) é Doutorando em Sociologia pela Universidade Estadual de Campinas (Unicamp) e Professor da Universidade Federal de Rondônia (UNIR). 


\section{REFERÊNCIAS BIBLIOGRÁFICAS}

BOURDIEU, P. 2007. Razões Práticas. Papirus : Campinas.

ELIAS, N. 1997. Os alemães : a luta pelo poder e a evolução do habitus nos séculos XIX e XX. Rio de Janeiro : J. Zahar.

FOUCAULT, M. 1977. Vigiar e Punir. Vozes : Petrópolis.

GOFFMAN, E. 2005a. A representação do Eu na vida cotidiana. Vozes : Petrópolis.

2005b. Manicômios, prisões e conventos. São Paulo : Perspectiva.

LEVI, P. 1988. É isto um homem? Rio de Janeiro : Rocco.
LOBO, L. 2004. Instituições e poder : racionalidade macropolítica e genealogia. Estudos de Psicologia (Natal), Natal, v. 9, n. 2, p. 309-316. Disponível em : http:// www.scielo.br/pdf/epsic/v9n2/a12v9n2.pdf. Acesso em : 2.ago.2009.

SCHEFF, T. 2007. The Goffman Legacy : Deconstructing/Reconstructing Social Science. Disponível em : http:// www.sscnet.ucla.edu/anthro/bec/papers/ goffman.pdf. Acesso em : 9.jul.2007.

SELIGMANN-SILVA, M. (org.). 2003. História, memória, literatura - o testemunho na Era das Catástrofes. Campinas : Unicamp.

WEBER, M. 2001. Metodologia das Ciências Sociais - parte II. São Paulo : Cortez. 


\section{INTERACTION, POWER AND TOTAL INSTITUTIONS: PRIMO LEVI'S NARRATIVE AND ERVING GOFFMANN'S MICROSOCIOLOGY}

\section{Robson dos Santos}

Through the biographical and literary narrative produced by a concentration camp survivor, the Italian Jew Primo Levi, describing the strategies of interaction and representation he adopted in order to go on living, this article engages in some reflections on Erving Goffmann's sociology. It seeks to apprehend processes of the production of subjectivity and individuality within a 'total institution' through looking at the role of social spaces in the construction of particular interactions, such as those that took place within a concentration camp, as described in Levi's book, If this is a man. This analysis leads to a reflection on the micro and the macro in Goffman's sociology, as well as an inquiry into the existence of a theory of institutions within it. Thus, in looking at this dimension of Goffman's work, through the prism of Levi's description of his experience in a total institution, we seek both to access a diversified narrative on one particular social space and to raise some questions regarding Goffman's views, particularly with regard to the ways in which his sociology gives dynamism to particular interactions, history and social structures that go beyond the terrain of interaction. Thus it seems that an analysis of interactions that are immanent to particular places does not enter into contradiction with the perception and analysis of wider social processes. The concentration camp, for example, instituted and produced its own sociabilities, although understanding the latter also includes the need to understand the emergence of Nazism, the history of persecuted groups and the meaning of the Holocaust in its relationship to the "civilizing process" or a particular form of modern rationality.

Keywords: symbolic interaction; literature; total institutions; Erving Goffman; Primo Levi. 
INTERACTIONS, POUVOIR ET INSTITUTIONS TOTALES: LE RÉCIT DE PRIMO LEVI ET LA MICROSOCIOLOGIE D'ERVING GOFFMAN

\section{Robson dos Santos}

A partir du récit biographique et littéraire produit par le survivant d'un camp de concentration - le juif italien Primo Levi - qui décrit ses stratégies d'interaction et représentation adoptées par le narrateursurvivant pour garantir sa vie, cet article esquisse quelques réflexions sur la Sociologie d'Erving Goffman. Le texte cherche à saisir les processus de production de la subjectivité et de l'individualité dans " une institution totale ", en comprenant le rôle des espaces sociaux dans la construction d'interactions particulières, comme celles qui se sont produites dans un camp d'extermination, à partir d'un récit figurant dans le livre de Primo Levi, « Si c'est un homme ». Cette analyse nous mène à la réflexion sur le micro et le macro en Sociologie de Goffman, aussi bien qu'à la recherche sur l'existence d'une théorie des institutions dans sa Sociologie. Donc, en pénétrant cette dimension de l'oeuvre de Goffman, avec l'aide de la description de l'expérience de Primo Levi dans une institution totale, nous cherchons aussi bien à avoir un autre récit sur l'espace traité qu'à soulever quelques questions pour la conception de Goffman, surtout en ce qui concerne les formes qui permettent que sa Sociologie dynamise les interactions particulières, l'histoire et les structures sociales extérieures au territoire interactionnel. Il nous semble qu'une analyse des interactions inhérentes aux locaux délimités n'est pas contradictoire à la perception et à l'analyse des processus sociaux amples : le camp d'extermination a, par exemple, institué et produit des sociabilités propres, dont l'entendement, toutefois, n'exclut pas le besoin de comprendre le processus de la montée du nazisme, l'histoire des groupés persécutés, ainsi que le sens de l'Holocauste par rapport au dénommé «processus civilisatoire » ou à une forme particulière de raisonnement moderne.

MOTS-CLÉS : interactions symboliques ; littérature ; institutions totales ; Erving Goffman ; Primo Levi. 